\title{
Recombinant Paraprobiotics as a New Paradigm for Treating Gastrointestinal Nematode Parasites of Humans
}

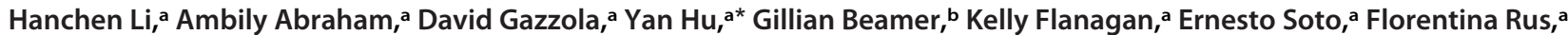 \\ Zeynep Mirza, a Austin Draper, ${ }^{c}$ Sridhar Vakalapudi, ${ }^{c}$ Cheryl Stockman, ${ }^{d}$ Perry Bain, ${ }^{d}$ Joseph F. Urban, Jr., e Gary R. Ostroff, ${ }^{a}$ \\ (D) Raffi V. Aroian ${ }^{a}$ \\ aProgram in Molecular Medicine, University of Massachusetts Medical School, Worcester, Massachusetts, USA \\ bDepartment of Infectious Disease and Global Health, Tufts University, North Grafton, Massachusetts, USA \\ cSynthetic Biomanufacturing Facility, Utah State University, Logan, Utah, USA

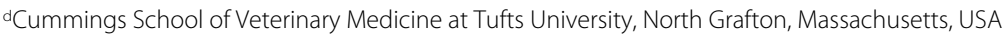 \\ eUnited States Department of Agriculture, Agricultural Research Service, Beltsville Human Nutrition Research Center, Diet, Genomics, Immunology Laboratory, Beltsville, \\ Maryland, USA
}

Hanchen Li, Ambily Abraham, and David Gazzola contributed equally to this article. Hanchen Li and David Gazzola ran all parasite assays; Ambily Abraham ran development of $\mathrm{IBaCC}$. Order picked at random between these three.

ABSTRACT Gastrointestinal nematodes (GINs) of humans, e.g., hookworms, negatively impact childhood growth, cognition, nutrition, educational attainment, income, productivity, and pregnancy. Hundreds of millions of people are targeted with mass drug administration (MDA) of donated benzimidazole anthelmintics. However, benzimidazole efficacy against GINs is suboptimal, and reduced/low efficacy has been seen. Developing an anthelmintic for human MDA is daunting: it must be safe, effective, inexpensive, stable without a cold chain, and massively scalable. Bacillus thuringiensis crystal protein 5B (Cry5B) has anthelmintic properties that could fill this void. Here, we developed an active pharmaceutical ingredient (API) containing B. thuringiensis Cry5B compatible with MDA. We expressed Cry5B in asporogenous B. thuringiensis during vegetative phase, forming cytosolic crystals. These bacteria with cytosolic crystals (BaCC) were rendered inviable (inactivated $\mathrm{BaCC}[\mathrm{IBaCC}]$ ) with food-grade essential oils. IBaCC potency was validated in vitro against nematodes. IBaCC was also potent in vivo against human hookworm infections in hamsters. IBaCC production was successfully scaled to 350 liters at a contract manufacturing facility. A simple fit-for-purpose formulation to protect against stomach digestion and powdered IBaCC were successfully made and used against GINs in hamsters and mice. A pilot histopathology study and blood chemistry workup showed that five daily consecutive doses of $200 \mathrm{mg} / \mathrm{kg}$ body weight Cry5B IBaCC (the curative single dose is $40 \mathrm{mg} / \mathrm{kg}$ ) was nontoxic to hamsters and completely safe. IBaCC is a safe, inexpensive, highly effective, easy-to-manufacture, and scalable anthelmintic that is practical for MDA and represents a new paradigm for treating human GINs.

KEYWORDS Bacillus thuringiensis, anthelmintic, crystal protein, gastrointestinal nematodes, helminths, hookworms, paraprobiotic, soil-transmitted helminths

mong the neglected tropical diseases, soil-transmitted helminths/nematodes (STHs/STNs) or gastrointestinal nematodes (GINs) collectively affect the largest number of people, with a global estimate of $>1.5$ billion infected individuals (1). Human GINs include hookworms (Ancylostoma duodenale, Ancylostoma ceylanicum, and Necator americanus), ascarids (Ascaris lumbricoides), and whipworms (Trichuris trichiura) (2). Human GIN parasites have an enormous impact on children, leading to physical growth stunting, cognitive impairment, malnutrition, anemia, impaired

Citation Li H, Abraham A, Gazzola D, Hu Y, Beamer G, Flanagan K, Soto E, Rus F, Mirza Z, Draper A, Vakalapudi S, Stockman C, Bain P, Urban JF, Jr, Ostroff GR, Aroian RV. 2021 Recombinant paraprobiotics as a new paradigm for treating gastrointestinal nematode parasites of humans. Antimicrob Agents Chemother 65:e01469-20. https://doi .org/10.1128/AAC.01469-20

Copyright $\odot 2021$ Li et al. This is an openaccess article distributed under the terms of the Creative Commons Attribution 4.0 International license.

Address correspondence to Gary R. Ostroff, gary.ostroff@umassmed.edu, or Raffi V. Aroian, raffi.aroian@umassmed.edu.

* Present address: Yan Hu, Biology Department, Worcester State University, Worcester, Massachusetts, USA.

Received 10 July 2020 Returned for modification 21 October 2020 Accepted 8 December 2020

Accepted manuscript posted online 14

December 2020

Published 17 February 2021 
physical fitness, loss of future income, decreased educational attainment, and defective immune responses to other infectious diseases (e.g., HIV, malaria, and tuberculosis) and vaccines (1-3). These parasites also cause significant complications for pregnant women and significant reductions in adult worker productivity, accounting for $>5$ million disability-adjusted life years and productivity losses of more than $\$ 100$ billion annually, with the majority of the morbidity attributed to hookworms $(2,4-7)$.

Only one class of drug, the benzimidazoles, is approved and suitable for single-dose mass drug administration $(8,9)$. GIN resistance to these drugs develops readily and is extremely common in veterinary medicine, where they have been used much longer and more intensely than in human medicine $(8,10)$. Against human GINs, these drugs have poor efficacy against whipworms. Low efficacy of albendazole (the most efficacious benzimidazole used in humans) against hookworms and Ascaris has been reported in many locales, with definitive benzimidazole resistance alleles detected in natural populations of human hookworms in Kenya and Brazil (11-20).

New mechanism-of-action anthelmintics are urgently needed in the pipeline, as the lead time for drugs to reach the market is years. As human GIN mass drug administration intensifies, further loss of benzimidazole efficacy is highly likely. However, developing new drugs for humans GINs is exceedingly difficult: (i) drug development is very expensive, costing several billions (21), a cost that cannot easily be recouped for diseases of the poorest peoples; (ii) the number of people impacted is enormous-any new therapy has to be massively scalable (an estimated 1.5 billion doses currently needed for children and women alone) and inexpensive (benzimidazoles are currently donated) (22); (iii) the therapy has to withstand harsh environmental conditions without a cold chain; and (iv) the therapy has to be safe and effective. Thus, the normal rules of "market-incentive" drug development do not apply. In fact, no drug has ever been developed for human GINs; all drugs used are expanded label uses of drugs developed for veterinary medicine. Of the two drugs used in mass drug administration today, albendazole was approved in humans in 1982 (23) and mebendazole was approved in 1974 (USA [24]). No new drugs have thus entered human GIN treatment for more than 30 years.

Bacillus thuringiensis crystal (Cry) proteins have the potential to offer a novel, natural, safe, and broad-spectrum anthelmintic alternative. $B$. thuringiensis spores are mass produced globally as a biopesticide, encompassing $\sim 75 \%$ of the bioinsecticide market (25). The main insecticidal components of $B$. thuringiensis are three-domain (3D)-Cry proteins that bind specifically to the invertebrate intestine, damaging the gut and killing the invertebrate target (26). 3D-Cry proteins have also been engineered into a range of food crops and are expressed in $\sim 100 \mathrm{mHa}$ of transgenic crops worldwide (27). More than a dozen different 3D-Cry proteins have been tested and found to be completely safe to vertebrates at doses of $\gg 1,000 \mathrm{mg} / \mathrm{kg}$ of body weight and are FDA/ EPA approved for ingestion $(28,29)$. The 3D-Cry protein Cry5B is related to the 3D-Cry proteins used as insecticides but targets nematodes instead. When administered orally as spore crystal lysates (SCLs) (a mix of $B$. thuringiensis spores and Cry protein crystals as they naturally occur), Cry5B is highly effective against GIN infections in hamsters, pigs, and dogs (30-34). The nematode receptor for Cry5B is an invertebrate-specific glycolipid absent in vertebrates (35).

Developing 3D-Cry proteins as large-scale ingested therapeutics compatible with human mass drug administration, however, requires a very different set of considerations than application as topical or transgenic biopesticides and insecticides. Here, we address these considerations, developing an active pharmaceutical ingredient (API) based on Cry5B compatible with safety, cost, scale, ease of production, and stability required for human mass drug administration.

\section{RESULTS}

Inactivated bacteria with cytosolic crystals. We reasoned that delivering Cry5B in a live bacterium (B. thuringiensis or otherwise) to humans would be problematic given 

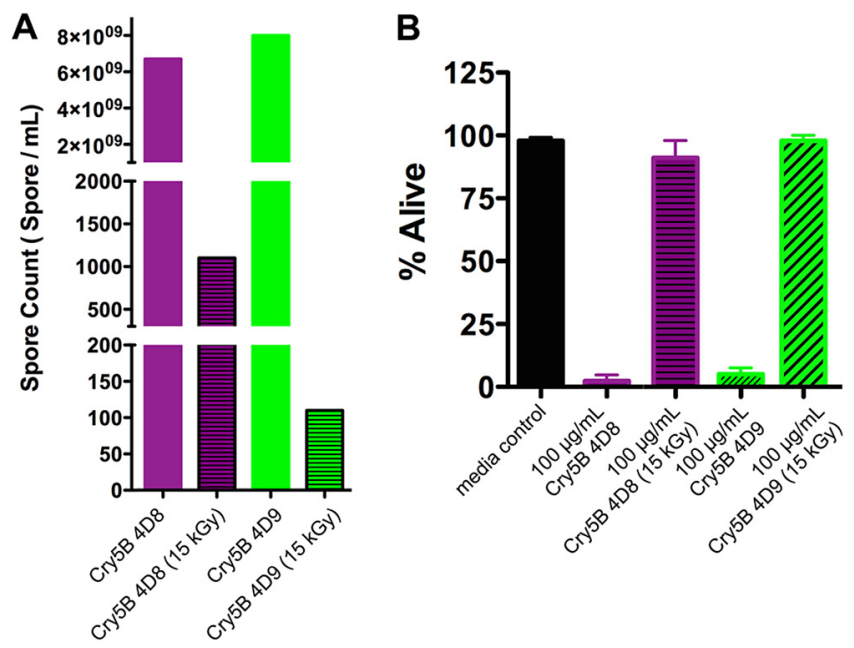

FIG 1 Effects of gamma irradiation on B. thuringiensis spore viability and Cry5B bioactivity. (A) Effect of $15 \mathrm{kGy}$ of gamma irradiation on spore counts for two different Cry-deficient $B$. thuringiensis strains (4.D.8 and 4.D.9) transformed with a Cry5B-expressing plasmid. (B) Comparison of Cry5B efficacy expressed in 4.D.8 and 4.D.9 on C. elegans viability at $100 \mu \mathrm{g} / \mathrm{ml}$ before and after 15-kGy irradiation. Labels without "15 kGy" indicate non-gamma-irradiated samples.

that (i) B. thuringiensis is closely related to Bacillus cereus, which can cause food poisoning, (ii) release of live recombinant bacteria has environmental concerns, because live bacteria in the soil could select for Cry5B resistance against free-living stages of hookworms, (iii) live bacteria could replicate in the human gastrointestinal tract (amplifying environmental and resistance concerns), (iv) there are uncertainties and significant safety concerns in the responses of billions of people to live bacteria, (v) degradation of live bacteria during storage could reduce potency and stability, and (vi) delivery of a stable live bacterial therapeutic around the world for mass drug administration would be difficult to achieve (36-40). Producing and delivering Cry5B as a purified protein is also problematic, as making enough purified protein cheaply and massively for mass drug administration is difficult to envision.

We therefore set out to deliver Cry5B, without purification of the protein, as part of a dead bacterial product (paraprobiotic [39]). To make a Cry5B paraprobiotic, we initially turned to and produced Cry5B spore crystal lysates, which have been used for most published in vivo studies of Cry5B anthelmintic efficacy as well as all $B$. thuringiensis insecticidal production and use $(31,33,34,41,42)$. We attempted to inactivate (kill) the spores without losing activity of the crystal protein using gamma irradiation (43). Although gamma irradiation resulted in a significant $\left(10^{6}\right.$ to $\left.10^{7}\right)$ reduction in spore viability (Fig. 1A), the procedure completely killed Cry5B antinematode activity (Fig. 1B). Preliminary studies using chemical treatment instead of gamma irradiation to inactivate spores without damaging crystal activity yielded similar, disappointing results.

We therefore decided that a better approach would be to express Cry5B in vegetative bacteria that could be more easily killed (inactivated). Based on our previous experiences and based on the fact that the inactivation process needs to be compatible with human ingestion, we hypothesized that food-grade monoterpenes derived from essential oils would be effective and safe antimicrobials for this application (44-47). We therefore expressed Cry5B in asporogenous (spo0A-deficient) B. thuringiensis so that the Cry5B crystals would be formed inside a vegetative $B$. thuringiensis without subsequent spore formation (Fig. $2 A)(48,49)$. We call such cells BaCC, for bacteria with cytosolic crystals. A number of food-grade monoterpenes were found that were capable of inactivation (killing) spo0A-deficient cells (see Table S1 in the supplemental material). When Cry5B was expressed in these cells and inactivated with terpene, the crystals stayed trapped within the cells, and the protein remained intact (Fig. 2A and B). A 

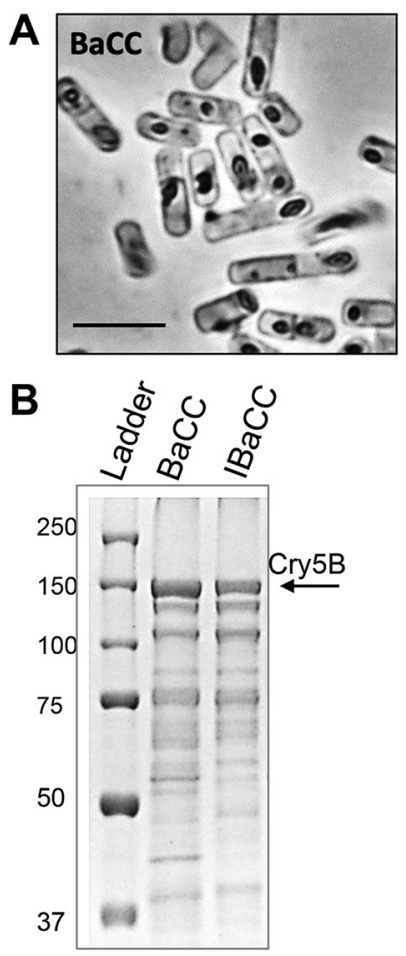

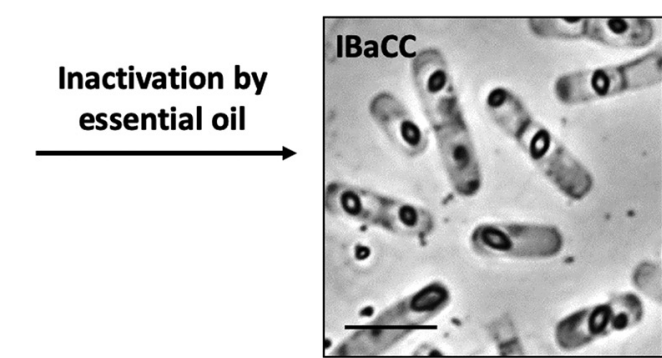

C

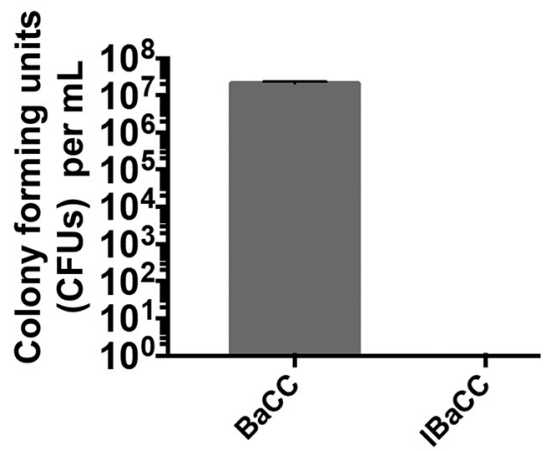

FIG $2 \mathrm{BaCC}$ (bacteria with cytosolic crystals) and IBaCC (Inactivated bacteria with cytosolic crystals). (A) spo0A-deficient $B$. thuringiensis cells expressing Cry5B from a vegetative promoter before (BaCC) and after (IBaCC) treatment with essential oil. Cry5B bipyramidal crystals (dark) are evident inside the bacteria pre- and posttreatment. Scale bars, $5 \mu \mathrm{m}$. (B) Protein gel showing Cry5B protein expressed in spo0A-deficient cells before and after essential oil treatment. (C) Spore counts from spo0A-deficient cells expressing Cry5B before and after essential oil treatment along with standard deviation (actual spore counts, $2.1 \times 10^{7} \mathrm{CFU} / \mathrm{ml}$ in $\mathrm{BaCC}$ and $0 \mathrm{CFU} / \mathrm{ml}$ in IBaCC).

$>10^{7}$-fold reduction in CFU was seen upon terpene treatment, with often no viable cells detected (Fig. 2C). We call these cells IBaCC, for inactivated BaCC.

IBaCC is an active nematicide. IBaCC was tested and quantified for antinematode activity initially against free-living stages of nematodes. Against the free-living nematode Caenorhabditis elegans, IBaCC (containing Cry5B crystals) intoxicated and killed L4/adult stages, whereas identically prepared IBa (inactivated bacteria with empty vector control; no Cry5B) did not (Fig. 3A). When tested against the free-living developing larval stages of the human hookworms A. ceylanicum and N. americanus, Cry5B IBaCC, but not vector-only IBa, was highly potent, strongly inhibiting larval development even at doses of 0.5 to $1 \mu \mathrm{g} / \mathrm{ml}$ (Fig. 3B).

We next tested $\mathrm{IBaCC}$ for antinematode activity against adult hookworm parasites in vitro. Cry5B IBaCC, but not IBa, was potent at intoxicating both species of adult parasitic hookworms at doses as low as $5 \mu \mathrm{g} / \mathrm{ml}$ (Fig. 4A and B). Cry5B in IBaCC showed a dose-dependent inhibition of motility similar to that in previously published studies with purified Cry5B (30). We had previously confirmed uptake of $0.4-\mu \mathrm{m}$ particles by adult hookworms (50). To confirm uptake of IBaCC by hookworms, we labeled IBaCC with rhodamine, which predominantly labels full-length Cry5B (Fig. 4C). (Rhodamine-labeled IBaCC was fully potent as seen by $100 \%$ dead adult hookworms after $24 \mathrm{~h}$ in $16 \mu \mathrm{g} / \mathrm{ml}$ Cry5B rhodamine-IBaCC). Visualization of the uptake of rhodamine IBaCC after $4 \mathrm{~h}$ by adult hookworms in vitro was confirmed by fluorescence microscopy (Fig. 4D). Taken together, these data indicate that Cry5B expressed in IBaCC is ingested by, and is highly active against, nematodes, even though the bacterium is not viable. Conversely, empty vector inactivated bacteria (IBa) without Cry5B are not active against nematodes. 

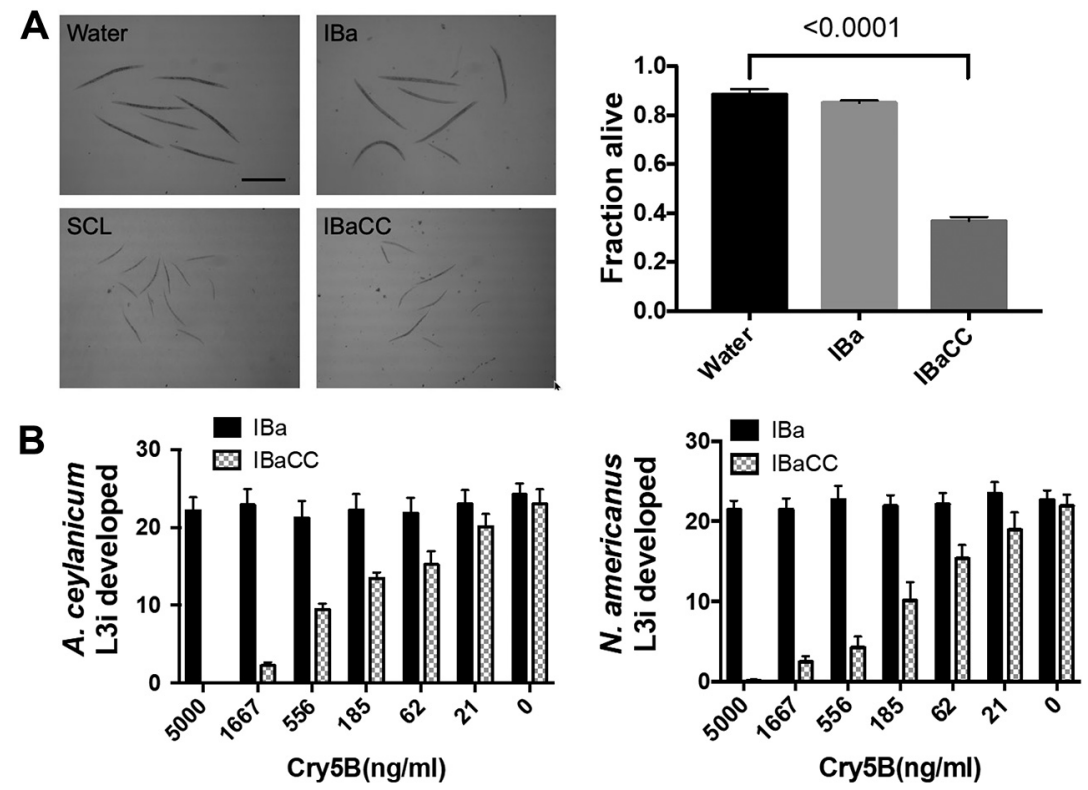

FIG 3 Efficacy of IBaCC in vitro against nematodes. (A) C. elegans. (Left) Photos of C. elegans N2 exposed to various conditions (spore crystal lysate [SCL] and IBaCC; both $40 \mu \mathrm{g} / \mathrm{ml}$ Cry5B). Scale bar, $200 \mu \mathrm{m}$. C. elegans was treated with azide to immobilize them just prior to imaging. (Right) Viability of C. elegans glp-4(bn2) L4 hermaphrodites under various conditions (IBaCC, $29 \mu \mathrm{g} / \mathrm{ml}$ Cry5B). $P$ value for comparison is from a one-tailed $t$ test. (B) Hookworm larval development. Plotted are the numbers of L3i larvae that developed from 60 hookworm eggs within 7 days ( $A$. ceylanicum, left; $N$. americanus, right). $x$ axes indicate the concentrations of Cry5B for IBaCC (IBa, 0 $\mathrm{ng} / \mathrm{ml}$ for all).

Cry5B IBaCC is a potent anthelmintic in vivo against both genera of human hookworms. We next tested whether $\mathrm{IBaCC}$ is efficacious in vivo against hookworms. Ancylostoma ceylanicum is an important zoonotic hookworm parasite of humans (51-54), and A. ceylanicum infections in hamsters are considered a good laboratory model for hookworm infections in humans (55). A. ceylanicum is also in the same genus as Ancylostoma duodenale, the second most common hookworm parasite in humans. Hamsters were infected with A. ceylanicum, and the infestations were allowed to proceed to mature adults with the appearance of parasite eggs (fecundity) excreted into the hamster feces $(31,33,56)$. These hamsters were then treated via gavage with a single-dose of IBaCC that was produced in our laboratory containing $10 \mathrm{mg} / \mathrm{kg}$ body weight Cry5B (Fig. 5A) or treated with IBa (vector-only control produced at the same time and processed identically to Cry5B IBaCC but lacking Cry5B). The impacts of the treatment on parasite reproduction (fecal egg counts) and intestinal hookworm burdens were assessed 5 days after treatment. Whereas IBa had no impact on hookworm burdens or fecal egg counts (Fig. 5A; see also Table S2 and Fig. S1), IBaCC had a strong impact, resulting in elimination of more than $93 \%$ of the hookworms (Fig. $5 A$; Table S2).

We also tested Cry5B IBaCC against the most common hookworms of humans, $N$. americanus, which can be maintained and studied in immunosuppressed hamsters (31). This hookworm infection is more difficult to treat (e.g., Necator, but not Ancylostoma, hookworms are recalcitrant to ivermectin treatment [57]). Cry5B IBaCC was highly effective against $N$. americanus hookworm infections in hamsters (Fig. 5B; Table S2) (assessed 5 days after treatment).

IBaCC is scalable and transferrable. We then looked at whether $B$. thuringiensis fermentation and Cry5B production and processing to IBaCC could successfully be transferred to and scaled up at a contract manufacturing facility. Our IBaCC strain and protocols were transferred to a contract manufacturing organization (CMO) at Utah State University. Fermentation of $\mathrm{Cry} 5 \mathrm{~B} \mathrm{BaCC}$ and processing to IBaCC was brought up 
A

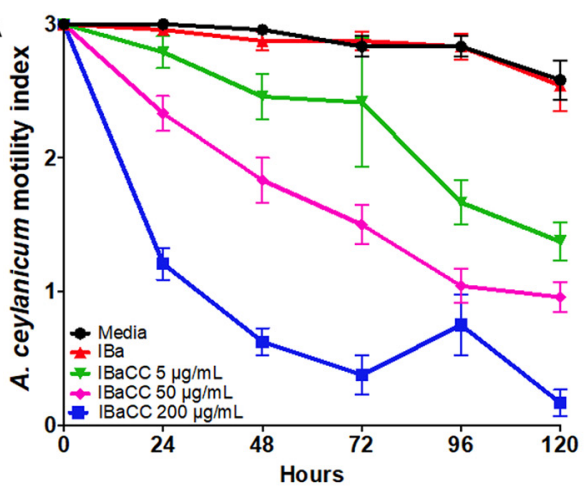

B

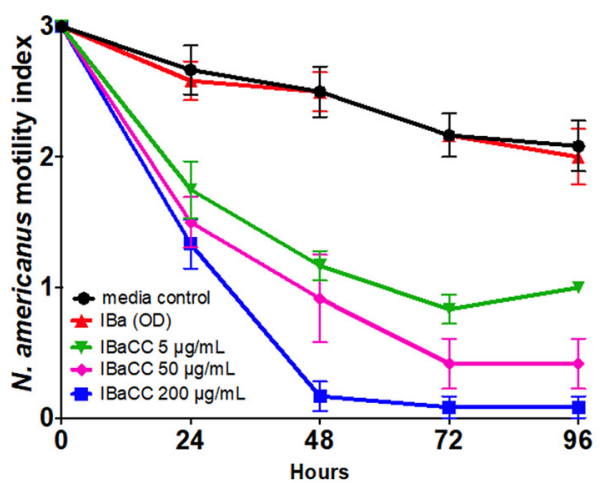

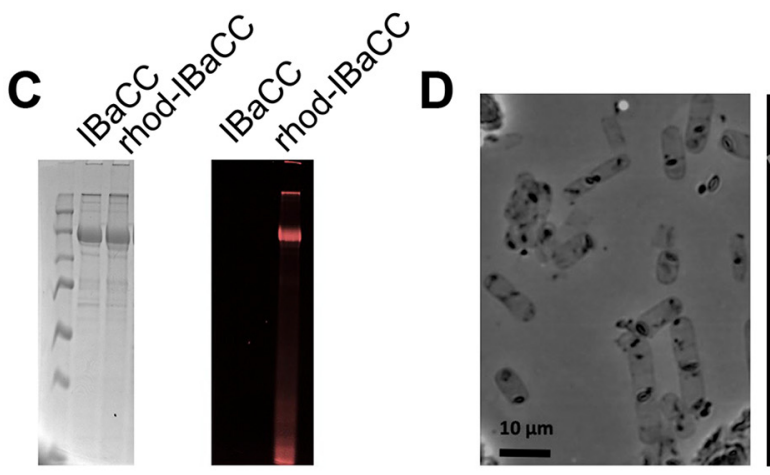
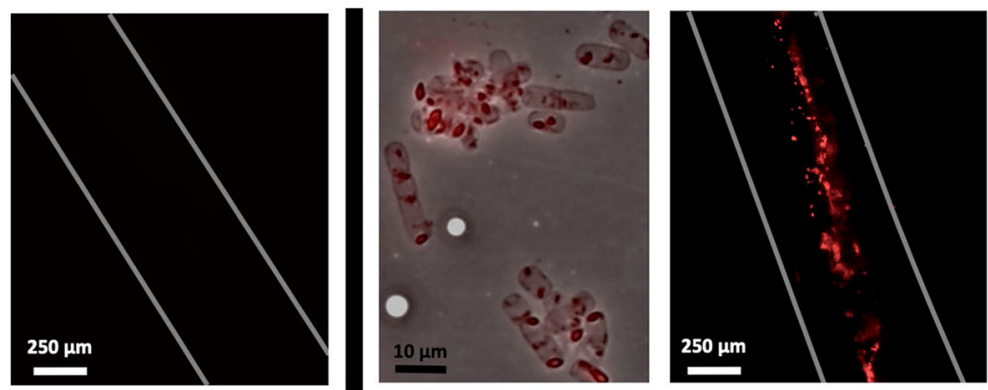

FIG 4 Impact of Cry5B IBaCC on adult hookworms in vitro. Adult hookworm motility over time at 5, 50, and $200 \mu \mathrm{g} / \mathrm{ml}$ Cry5B for A. ceylanicum adults (A) and $N$. americanus adults (B) in vitro averaged over three independent trials. In all figures, plots show averages and standard errors. (C) (Left) SDS-PAGE gel showing IBaCC before (IBaCC) and after (rhod-IBaCC) labeling with rhodamine. (Right) UV fluorescence image of same gel, showing predominant labeling of full-length Cry5B band for rhod-IBaCC. (D) Uptake of rhod-IBaCC. (Left) Bright-field image of IBaCC and rhodamine fluorescence image of adult hookworm fed IBaCC for $4 \mathrm{~h}$. (Right) Bright-field image of rhod-IBaCC and rhodamine fluorescence image of adult hookworm fed rhod-IBaCC for $4 \mathrm{~h}$. Uptake of rhodamine-labeled Cry5B crystals is evident.

to the 350 -liter scale by $\mathrm{CMO}$. Cry5B IBaCC produced at the $\mathrm{CMO}$ was then tested in vivo against $A$. ceylanicum hookworm infestations in hamsters at 2 and $6 \mathrm{mg} / \mathrm{kg}$ body weight Cry5B. Single-dose IBaCC produced at the manufacturing facility was effective at reducing $A$. ceylanicum burdens and parasite fecal egg counts in hamsters relative to that for a water control (Fig. 6A; Table S2) (assessed 5 days after treatment). Increasing the dose of Cry5B in this large-scale $\mathrm{IBaCC}$ production run to $15 \mathrm{mg} / \mathrm{kg}$ essentially cured the parasite infestation (Fig. 6B; Table S2). Efficacy was similar to that for inhouse produced IBaCC (Fig. 5 compared to Fig. 6).

Cry5B IBaCC can be made into a fit-for-purpose formulation and dried down. Previous work has shown that the potency of Cry5B spore crystal lysates is enhanced by addition of a pretreatment with cimetidine to neutralize stomach acid. However, pretreatment with a drug such as cimetidine is not compatible with mass drug administration. We therefore tested whether the development of a safe and simple "fit-for-purpose" formulation compatible with mass drug administration, notably, simultaneous delivery with sodium bicarbonate, would be protective for IBaCC. IBaCC was given alone or simultaneously with sodium bicarbonate to hookworm-infected hamsters. We found that acid neutralization with sodium bicarbonate given simultaneously with IBaCC slightly but significantly increased IBaCC efficacy against hookworms (Fig. 7A; Table S2).

Delivery of IBaCC as a powder (and not as a liquid slurry as in the above-described experiments) is also a critical parameter for storage and mass drug administration (MDA). We therefore freeze-dried IBaCC into a powder and compared the efficacy of the same batch of IBaCC before and after freeze-drying (given per os as a powder suspension in water). As shown (Fig. 7B; Table S2), freeze-drying had no impact on IBaCC in vivo efficacy. 

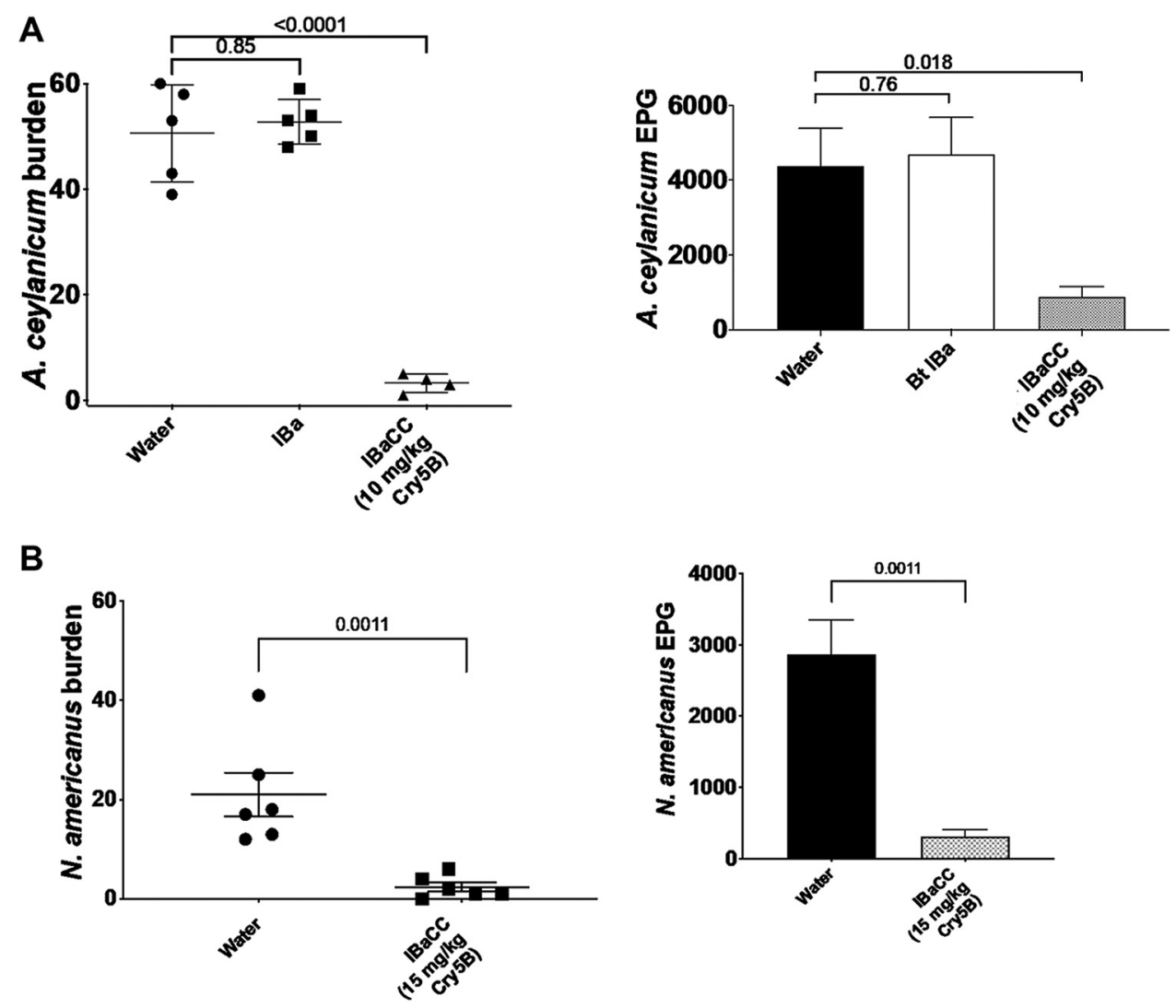

FIG 5 Efficacy of IBaCC produced in the laboratory in vivo against both human hookworm genera. (A) Shown are mean A. ceylanicum hookworm burdens (left) and fecal egg counts (right) in infected hamsters treated with water control, IBa, or IBaCC containing Cry5B. Here and in subsequent figures, error bars are standard errors. EPG, eggs per gram of feces. (B) Mean N. americanus hookworm burdens (left) and fecal egg counts (right) in infected hamsters treated with water control or IBaCC containing Cry5B.

Efficacy of freeze-dried IBaCC simultaneously delivered with sodium bicarbonate was also tested against a different, luminal-feeding (58) intestinal parasitic nematode in a different host, namely, Heligmosomoides polygyrus bakeri infections in mice. These data confirm that this simple fit-for-purpose IBaCC formulation is effective against a different parasitic nematode in a different rodent host (Fig. 8; Table S2). The single-dose efficacy seen $(53 \%$ reduction in worm burdens and $85 \%$ reduction in fecal egg counts, single dose $40 \mathrm{mg} / \mathrm{kg}$ Cry5B) was superior to that shown in previous studies using Cry5B SCL with this parasite $(31,42)$ and is $>20$ to $80 \times$ more effective on a molar basis than ivermectin or albendazole against this same parasite (56).

Pilot preclinical toxicology study. Cry proteins have a stellar safety record and are considered nontoxic to vertebrates even at high doses, and the bacterium delivering $\mathrm{IBaCC}$ is dead (inactivated). Thus, IBaCC is predicted to be completely safe. However, $\mathrm{IBaCC}$ represents a new form for delivering a Cry protein. Thus, we performed a pilot maximal Cry5B dose safety study (see Fig. S2) using histopathology and blood chemistry as readouts.

Sixteen uninfected hamsters (eight female and eight male) were split into two groups. Half the hamsters (four female and four male) were given $200 \mathrm{mg} / \mathrm{kg}$ Cry5B IBaCC per os daily for 5 days. Since a single $40 \mathrm{mg} / \mathrm{kg}$ dose of Cry5B is curative for hookworms (31), each dose represents $5 \times$ the curative dose, and cumulatively, $5 \times$ the required number of doses were given. The other half of the hamsters received equal volumes of water per os on each of the 5 days. Three days after the final treatment, half of the hamsters in each group were sacrificed (acute group). All major organs were immediately dissected, fixed in formalin, sectioned, and stained, looking for signs of 

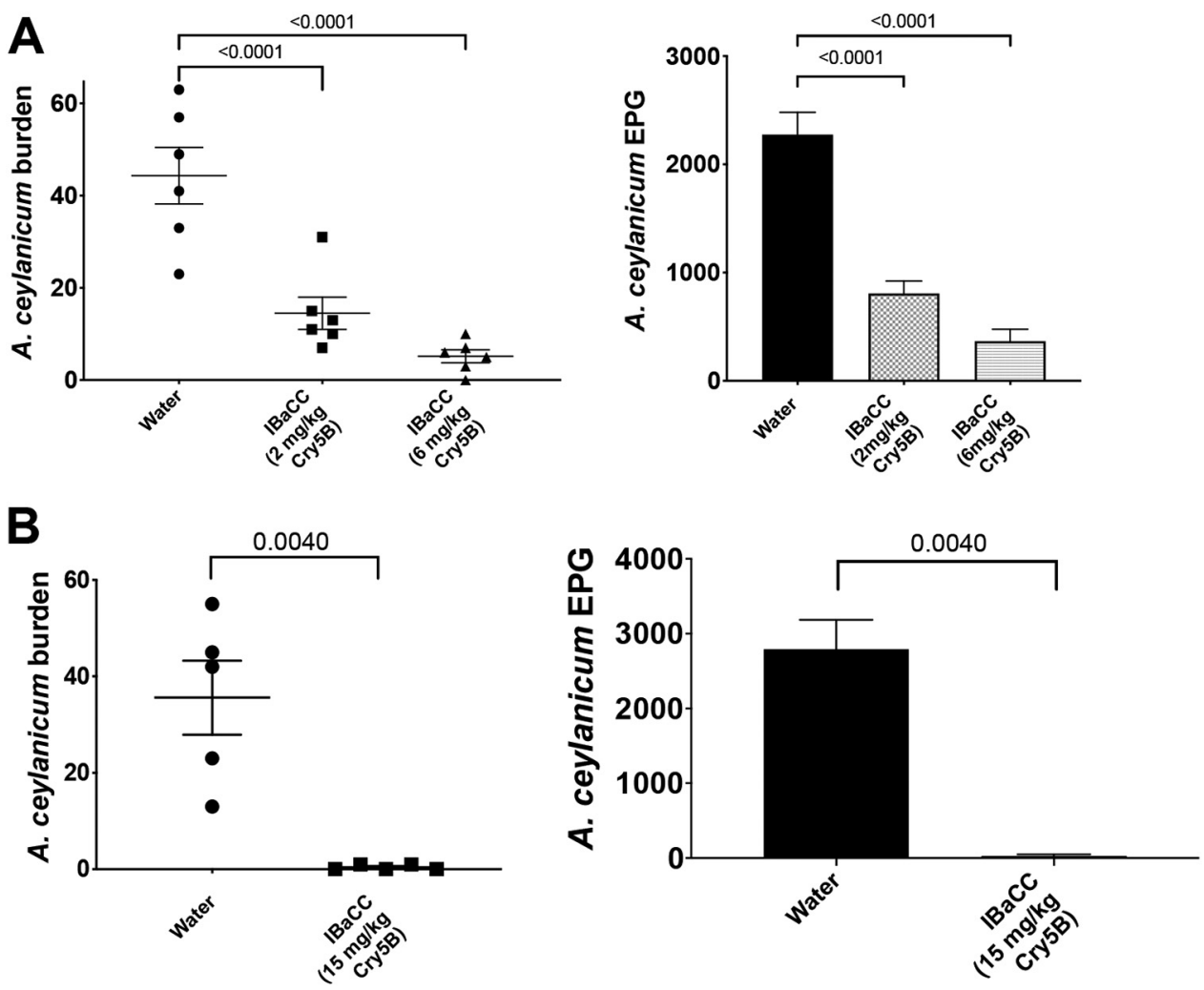

FIG 6 Efficacy of production facility IBaCC in vivo against $A$. ceylanicum hookworms. (A) Dose response of $A$. ceylanicum burdens (left) and fecal egg counts (right) in infected hamsters treated with water control or CMOproduced IBaCC containing Cry5B. (B) A. ceylanicum burdens (left) and fecal egg counts (right) in infected hamsters treated with water or CMO-produced $15 \mathrm{mg} / \mathrm{kg}$ Cry5B in IBaCC. EPG, eggs per gram of feces. $P$ values for relevant comparisons are given.

disease and lesions (see Materials and Methods for details). Ten days after the final treatment, the remaining half of the hamsters in each group were sacrificed (recovery group). The acute group would permit observation of any short-term adverse consequences of treatment, whereas the recovery group would permit observation of the resolution of adverse consequences seen in the acute group (if any). After staining, 274 sections from all major organs and tissues were examined in a blinded manner and scored by a board-certified pathologist.

The full results are presented in Table S3. Based on this maximal dose pilot treatment study, there were no significant differences seen between water and $\mathrm{IBaCC}$ groups. There were also no significant differences seen between the acute and recovery groups comparing across other groups, and no significant differences seen between males and females comparing across other groups. No significant pathologies were seen in any groups.

After sacrifice, blood samples were also collected and analyzed for blood chemistry, with a focus on enzymes that could be indicative of renal or hepatic injury (alanine aminotransferase [ALT], gamma-glutamyl transferase [GGT], aspartate aminotransferase [AST], bilirubin, blood urea nitrogen or urea, and creatinine). Comparison of hamsters in the water versus Cry5B IBaCC groups showed no statistical difference in any of these levels (see Table S4), consistent with high level of safety and lack of toxicity.

Repeated maximal dosing of IBaCC appeared to be completely safe and nontoxic to hamsters based on this pilot histopathology and blood chemistry study. Acute and chronic good laboratory practice (GLP) toxicology studies with larger sample sizes are planned in the future with clinical-grade Cry5B IBaCC. 

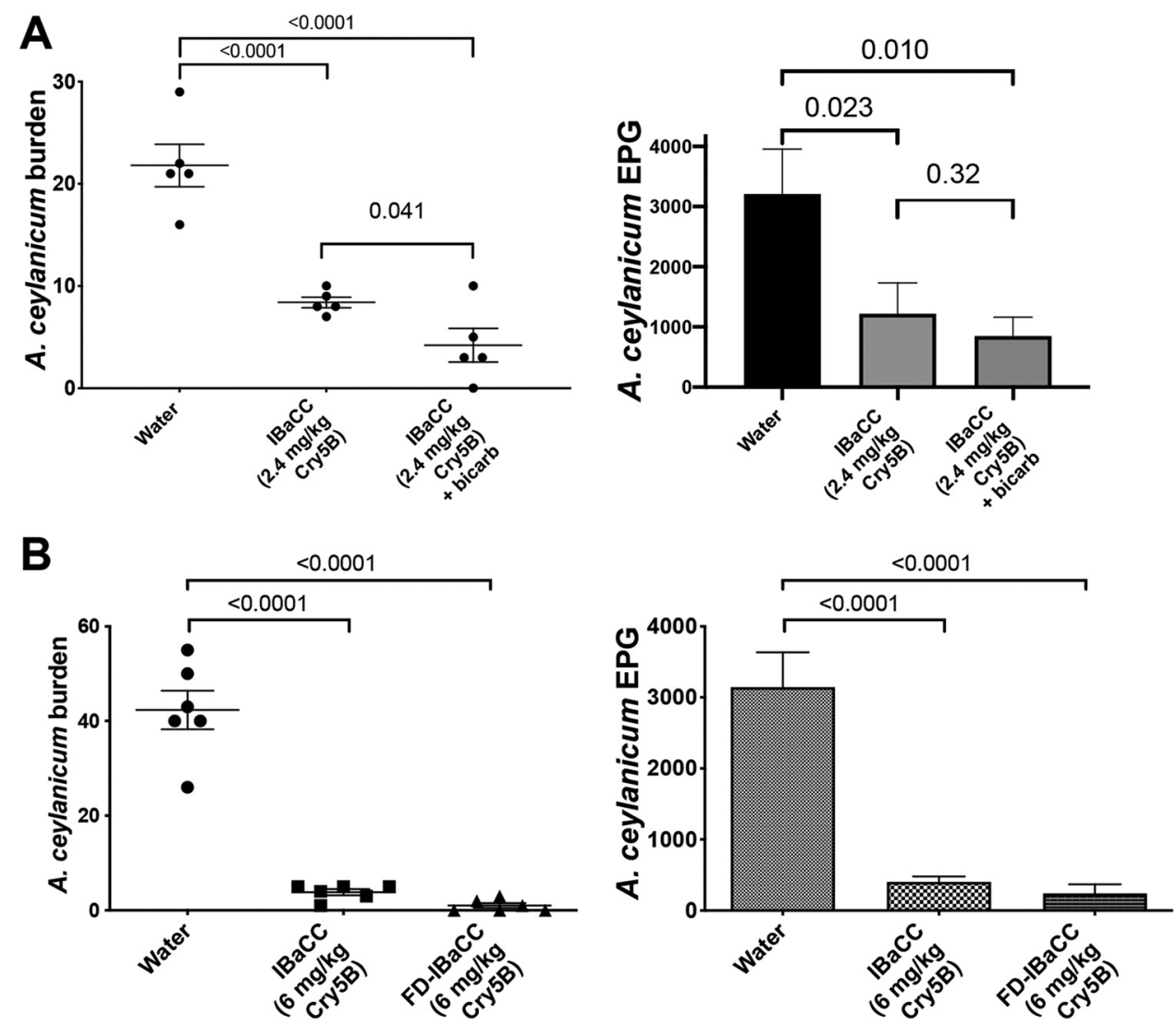

FIG 7 Fit-for-purpose formulation studies for Cry5B IBaCC. (A) Mean A. ceylanicum hookworm burdens (left) and fecal egg counts (right) in infected hamsters treated with water control, IBaCC, or IBaCC mixed with sodium bicarbonate. No cimetidine pregavage was used in these experiments. (B) Mean A. ceylanicum hookworm burdens (left) and fecal egg counts (right) in infected hamsters treated with water control, IBaCC, or the same batch of IBaCC freeze-dried (FD). $P$ values for relevant comparisons are given.

\section{DISCUSSION}

The primary aim of this study was to develop and demonstrate a practical scalable therapeutic for treating GIN infections in humans. The importance of these aspects of human anthelmintics are too often neglected. To date, there has been no drug developed specifically for human GINs. All drugs used for human GIN treatment came from
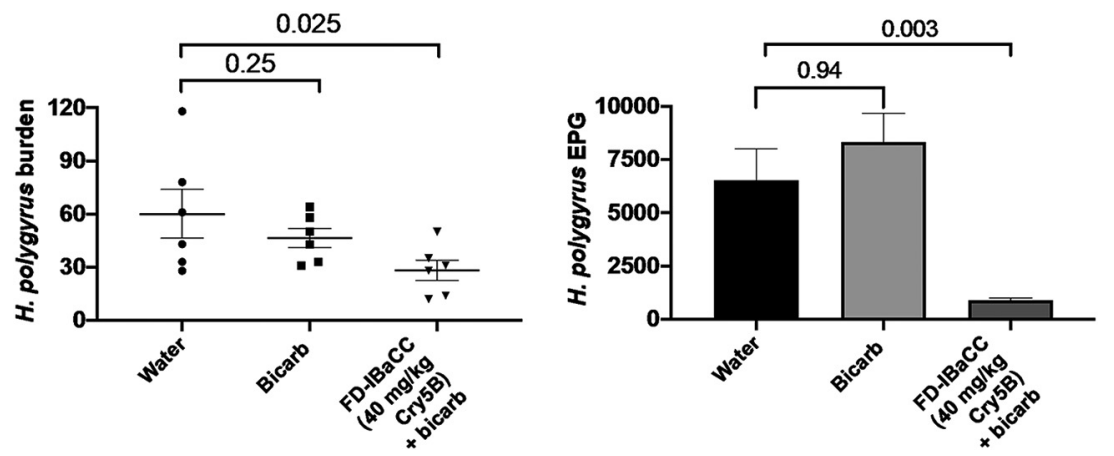

FIG 8 Confirmation of fit-for-purpose Cry5B IBaCC efficacy against a different, luminal feeding parasite in a second host. Mean $H$. polygyrus bakeri burdens (left) and fecal egg counts (right) in infected mice treated with water, sodium bicarbonate, or single-dose freeze-dried (FD) Cry5B IBaCC mixed with sodium bicarbonate. The FD-IBaCC used was an independent batch from that used for the data shown in Fig. 7. 
drugs developed for veterinary targets (59). Furthermore, the availability of current drugs for human mass drug administration relies upon off-patent drugs that are donated (22). Anthelmintics for human GINs need to be effective, safe, stable, scalable, compatible with mass drug administration, and low cost.

$B$. thuringiensis Cry proteins, one of which has anthelmintic activity against human GINs $(31,34)$, have many of the characteristics required. $B$. thuringiensis spore crystal lysates are massively produced around the world for agriculture (75\% of the biopesticide market [25]), are shelf stable, and low cost. B. thuringiensis Cry proteins have a superb track record of safety for more than 6 decades of use in agriculture (caterpillar/ beetle) and vector (black fly and mosquito) control $(28,29,60)$. Indeed, the specific receptor for Cry5B in nematodes is restricted to invertebrates (35). However, the use of Cry proteins as insecticidal sprays and incidental exposure in people and in $>100 \mathrm{MHa}$ of transgenic crops at subanthelmintic doses is a "far cry" from their use as purposely eaten therapeutics in much higher doses and as a broad-spectrum anthelmintic. For example, many commercial $B$. thuringiensis strains contain enterotoxin genes associated with food poisoning in $B$. cereus (61-63). Although strain selection could help mitigate some of this concern, there are clearly major regulatory hurdles associated with using live $B$. cereus family bacteria as a purposely ingested therapeutic as opposed to an agricultural spray $(64,65)$.

Here, for the first time, we describe a specific $B$. thuringiensis Cry protein form developed to deliver Cry proteins as an ingestible therapeutic to vertebrates. This new form, Cry5B IBaCC, presents the Cry5B crystal protein as a crystal contained within the cell wall "ghost" of a dead vegetative bacterium, or paraprobiotic. Cry5B IBaCC is efficacious in vivo against both genera of blood-feeding human hookworms and one lumenfeeding parasitic nematode, $H$. polygyrus bakeri. IBaCC and/or the crystals inside the bacterium are ingested by the parasites, causing them to be intoxicated by damage to their intestinal cells. Efficacy in vivo is excellent, with a near complete clearance of hookworms at $15 \mathrm{mg} / \mathrm{kg}$. On a molar concentration scale, Cry5B IBaCC is $175 \times$ more effective at clearing hookworms than albendazole (66). High efficacy of Cry5B IBaCC against Haemonchus contortus infections in small ruminants (sheep) has also just been reported (67).

Cry5B IBaCC production was successfully transferred to an industrial CMO and scaled up to 350 liters. Cry5B IBaCC is also compatible with simple fit-for-purpose formulations, such as sodium bicarbonate (e.g., Alka-Seltzer), and can be dried down while retaining full activity. Importantly, this new form of Cry5B, IBaCC, appeared safe in a maximal multidose acute toxicology study based on histopathology and blood chemistry workups. These findings confirm the lack of Cry5B toxicity reported in all previous rodent, livestock, and companion animal studies (30-32, 34, 42). Our current focus is optimizing the Cry5B IBaCC production strain for increased Cry5B yields, scale up, and GLP toxicology studies prior to initiating first-in-human clinical trials.

By killing the Cry5B-containing vegetative bacteria, but still using the whole fermentation, a host of issues associated with live bacteria (e.g., stability, safety, and environmental contamination) or protein purification are obviated. Because the product is taken straight out of the fermenter, briefly incubated with essential oil, washed, and then ready for use, the process is simple and inexpensive. It could even be carried out locally in countries of GIN endemicity. Because the bacterium is killed, there are fewer issues with (i) degradation of the product over time as the bacterium dies, (ii) regulatory issues associated with a product that is changing over time, such as for live bacteria, as viability decays on the shelf, (iii) selection of resistance with live bacteria replicating in the environment or in the GI tract, (iv) release of live recombinant bacteria into the environment, and ( $v$ ) any potential toxicity associated with live bacteria in general and with enterotoxins associated with $B$. cereus family of bacteria specifically (see above). These properties should make IBaCC readily acceptable to drug and environmental regulatory agencies.

These studies validate IBaCC as a powerful, practical, safe, and deployable 
anthelmintic compatible with MDA that can safely and effectively deliver not only Cry5B but also other antinematode $B$. thuringiensis Cry proteins (68) for anti-GIN therapy. IBaCC uniquely and practically harnesses the safety, massive scalability, history, and power of $B$. thuringiensis and $B$. thuringiensis Cry proteins against one of the most prevalent and intractable diseases of the poorest populations on earth. IBaCC promises new hope for a new arsenal of anthelmintics against the most common parasites of humans and animals.

\section{MATERIALS AND METHODS}

Nematodes. (i) Medium and reagents. Reagents for hookworm culture medium (HCM), including RPMI 1640 medium, fetal bovine serum (FBS), penicillin-streptomycin, and fungizone antimycotic, were all purchased from Gibco, USA. Dexamethasone 21-phosphate disodium salt (DEX) (catalog number [cat. no.] D1159-5G) and cimetidine (cat. no. C4522-5G) were purchased from Sigma-Aldrich, USA. Cimetidine was prepared and dosed as described previously (69).

(ii) Caenorhabditis elegans. Caenorhabditis elegans was maintained using standard techniques (70). The following strains were used in this study: N2 Bristol (wild type) and glp-4(bn2). For images shown in Fig. 3 (growth assay), hatched N2 L1 worms were incubated for 3 days at $25^{\circ} \mathrm{C}$ using a standard L1 growth assay $(68,71)$ in 48 -well plates containing an Escherichia coli food source and with treatments as indicated. Assayed worms were stilled with sodium azide, washed, and arranged for imaging in spot plates. Images were taken with a dissecting microscope fitted with a camera. The bioactivity of Cry5B in freeze-dried and irradiated freeze-dried SCLs (Fig. 1) was confirmed against C. elegans by a mortality assay for $48 \mathrm{~h}$ at $25^{\circ} \mathrm{C}$ as described previously (71-73). For the Fig. 3 lethality study, assays were carried out with $g / p-4(b n 2)$ hermaphrodites incubated at $25^{\circ} \mathrm{C}$ for 6 days. The use of $g / p-4(b n 2)$, which prevents production of progeny at the nonpermissive temperature by the hermaphrodites, is routine for these mortality assays, which would otherwise be complicated via internal hatching of larvae that sometimes occurs when adult C. elegans is intoxicated with Cry proteins (74-77). Data represent the averages and standard errors from three independent experiments with approximately 60 worms per experiment (180 total), except for the IBa control in Fig. 3A (two independent experiments).

(iii) Animals and parasites. Ancylostoma ceylanicum and Necator americanus life cycles were maintained as previously published (31). Three- to 4-week-old male Golden Syrian hamsters (HsdHan:AURA) were purchased from Envigo (USA) and were infected at approximately 4 to 5 weeks of age with either $\sim 150$ A. ceylanicum third-stage infectious larvae (L3i) orally or $\sim 400 \mathrm{~N}$. americanus L3i subcutaneously. Hamsters were provided with food and water ad libitum. The Heligmosomoides polygyrus bakeri life cycle was maintained at the United States Department of Agriculture (USDA) as described previously (78). Infectious-staged larvae were shipped to University of Massachusetts Medical School. All animal experiments were carried out under protocols approved by the University of Massachusetts Medical School. All housing and care of laboratory animals used in this study conform to the NIH Guide for the Care and Use of Laboratory Animals in Research (18-F22) and all requirements and all regulations issued by the USDA, including regulations implementing the Animal Welfare Act (P.L. 89-544) as amended (18-F23).

(iv) In vitro assays with parasites. Egg-to-larva assays were carried out as described previously (41). Adult hookworm in vitro assays were carried out essentially as described previously $(32,56)$. Briefly, for A. ceylanicum, three adult hookworms per well were placed in $500 \mu \mathrm{l}$ hookworm medium in a 24-well format with the designated treatment using four wells/condition and then set up three independent times. $N$. americanus parasites were similarly tested but with only three wells per condition, because the number of adult parasites per hamster is more limited. For all conditions, there were roughly the same numbers of male and female worms. Hookworm adults were scored on a 0 to 3 scale $(0$, nonmotile even when touched; 1 , nonmotile unless touched; 2 , slowly motile; 3, fully motile) as described previously $(32,56)$.

For rhodamine-labeled IBaCC (rhod-IBaCC), IBaCC was resuspended in phosphate buffer $(0.1 \mathrm{M}, \mathrm{pH}$ 7) at a concentration of $2 \mathrm{mg} \mathrm{Cry5B/ml}$. Rhodamine isothiocyanate (RITC) was dissolved at $5 \mathrm{mg} / \mathrm{ml}$ in dimethyl sulfoxide. RITC solution $(60 \mu \mathrm{l})$ was added to a $1-\mathrm{ml}$ suspension of IBaCC, and the sample was incubated with constant mixing in the dark at room temperature for $18 \mathrm{~h}$. Tris buffer $(60 \mu \mathrm{l}, 1 \mathrm{M}, \mathrm{pH})$ was added, and the reaction mixture was stirred for an additional $15 \mathrm{~min}$ to quench free RITC. The sample was centrifuged to collect rhod-IBaCC, and the pellet was washed with water to remove physisorbed dye. Uptake of IBaCC and rhod-IBaCC in A. ceylanicum was evaluated at a concentration of $16 \mu \mathrm{g} \mathrm{Cry5B/ml} \mathrm{using} \mathrm{three} \mathrm{adult} \mathrm{hookworms} \mathrm{per} \mathrm{well} \mathrm{in} \mathrm{a} \mathrm{24-well} \mathrm{format.} \mathrm{Worms} \mathrm{were} \mathrm{evaluated} \mathrm{by}$ fluorescence microscopy for particle uptake at $1.5,4$, and $24 \mathrm{~h}$.

(v) In vivo studies. The $A$. ceylanicum and $N$. americanus in vivo experiments were carried out as described previously $(31-33,56)$. Briefly, fecal egg counts for $A$. ceylanicum were taken on days 17 to 18 postinoculation to establish groups with roughly equal infectivity, and then the animals were treated with a single-dose gavage on day 18 postinoculation. Fecal egg counts were taken again on days 22 to 23 postinoculation, and parasite burdens in the small and large intestine were assessed on day 23 postinoculation. Fecal egg counts for $N$. americanus were taken on days 55 to 56 postinoculation to establish groups with roughly equal infectivity, and then the animals were treated with a single-dose gavage on day 56 postinoculation. Fecal egg counts were taken again on days 60 to 61 postinoculation, and parasite burdens in the small and large intestines were assessed on day 61 postinoculation. In Fig. 5, a slightly lower dose was used against $A$. ceylanicum than against $N$. americanus based on previous data suggesting that the former parasite was slightly more sensitive to Cry5B treatment in vivo in hamsters 
(31). For all in vivo experiments, except where sodium bicarbonate was used (Fig. 7A and all of Fig. 8; see also Fig. $\mathrm{S} 1$ in the supplemental material), cimetidine was prepared and given per os 15 min ahead of Cry5B administration, as previously described (31). For experiments with sodium bicarbonate, Cry5B IBaCC was given per os in $200 \mu \mathrm{l} 0.1 \mathrm{M}$ sodium bicarbonate. Freeze-dried IBaCC was prepared as for SCL (described below). Experiments using H. polygyrus bakeri were carried out as described previously (31). Briefly, fecal egg counts were taken on days 14 to 15 postinoculation to establish groups with roughly equal infectivity, and then the animals were treated with a single-dose gavage on day 15 postinoculation. Fecal egg counts were taken again on days 19 to 20 postinoculation, and parasite burdens in the small and large intestines were assessed on day 20 postinoculation.

Bacteria. (i) Spore and spore crystal lysates. For the experiments shown in Fig. 1, B. thuringiensis subspecies kurstaki HD1-4D8 and HD1-4D9 were ordered through the Bacillus Genetic Stock Center. Both crystal-deficient $B$. thuringiensis strains were transformed with a plasmid containing the Cry5B gene (72). Spore lysates (SLs; HD1 Cry-deficient strains) and spore crystal lysates (SCLs; HD1 strains transformed with Cry5B plasmid) were prepared using standard methods $(42,72)$ and then stored at $-80^{\circ} \mathrm{C}$ until use. For freeze-drying, SL and SCL samples stored at $-80^{\circ} \mathrm{C}$ for at least $12 \mathrm{~h}$ were loaded into a FreeZone 1-liter benchtop freeze-dry system (Labconco catalog number 7740020). The condenser was set to $-60^{\circ} \mathrm{C}$ and the vacuum at $22 \mathrm{mTor}$. Irradiation of freeze-dried SL and SCL was accomplished with a cobalt-60 irradiation source at the University of Massachusetts Lowell Radiation Laboratory. Irradiation doses of 5, 10, 15, 20, 25, 30, and 60 kGy were initially tested, and $15 \mathrm{kGy}$ was chosen as the lowest radiation dose with a strong effect on spore viability. To determine the number of spores, $10 \mathrm{mg}$ lyophilized powder was taken under sterile conditions before and after irradiation, transferred into $1 \mathrm{ml}$ of sterile distilled water in microtubes, and homogenized by vortexing. One hundred microliters of the SL or SCL suspensions was removed from each sample and incubated at $80^{\circ} \mathrm{C}$ in a water bath for 20 min to kill any vegetative cells and then diluted by a 10 -fold dilution series. One hundred microliters of diluted samples (from $10^{6}$ to $10^{9}$ ) was spread on top of LB agar plates in triplicates with Rattler plating beads and incubated overnight at $30^{\circ} \mathrm{C}$. Colonies on each plate were manually counted.

(ii) IBa and IBaCC strain construction and maintenance. The promoter region of cry3A (48) was fused to the coding region of $c r y 5 B$ and its downstream terminator via the $\mathrm{N}$-terminal Clal restriction site. This $P_{c r y 3 A}-C r y 5 B$ expression construct was subsequently cloned into pHT3101 (79). The resulting plasmid, pHY159, was electroporated into $B$. thuringiensis strain $407 \Delta$ spo0A::kan (49). The entire cry5B insert was sequenced to confirm no mutations were included. Single colonies of $407 \Delta$ spoOA::kan cells harboring pHY159 or pHT3101 empty vector control (EVC) were grown in nutrient-rich $3 \times$ LB with erythromycin $(10 \mu \mathrm{g} / \mathrm{ml})$ at $30^{\circ} \mathrm{C}$ with shaking at $250 \mathrm{rpm}$ for 2 to 3 days. Outsourced cultures at a biomanufacturing facility were similarly grown in a fermenter with constant monitoring and adjustments of $\mathrm{pH}$ and oxygen levels at $30^{\circ} \mathrm{C}$ with $150 \mathrm{rpm}$ agitation for $48 \mathrm{~h}$. In both cases, cells were harvested by centrifugation and resuspended to $10 \%$ initial volumes in ice-cold water. Tenfold concentrations of harvested cultures were inactivated with the addition of food-grade monoterpene or essential oil at $0.1 \%$ final concentration and incubated with gentle agitation at room temperature for $15 \mathrm{~min}$. Inactivated cultures were then centrifuged, washed with water, and resuspended in saline at $10 \%$ the initial volume. For all experiments except those shown in Fig. 7B, residual terpenes were extracted with corn oil ( $20 \%$ final volume) with gentle agitation at room temperature for $2 \mathrm{~h}$. We have not found any impact on in vivo efficacy with or without this step. IBaCC was recovered after centrifugation and three washes with ice-cold water. Concentrated $(10 \times)$ samples were removed for several analyses, including SDS-PAGE (for Cry5B content and quantification), cell density, cell viability, and nematode-killing assays.

For experiments shown in Table S1, B. thuringiensis $407 \Delta$ spo0A::kan cells transferred with pHY159 were grown in Luria broth overnight at $30^{\circ} \mathrm{C}$ in $10 \mu \mathrm{g} / \mathrm{ml}$ erythromycin to saturation. The next day, 100 $\mu \mathrm{l}$ of terpene or essential oil (80) was added to $100 \mu \mathrm{l}$ of overnight culture to a final volume of $1 \mathrm{ml}$ in Luria broth plus erythromycin (the following terpenes and essential oil used were: geraniol, eugenol, thymol, citral, carvacrol, cinnamic aldehyde, tea tree, limonene, and undecanoic acid). Tubes were shaken overnight at $30^{\circ} \mathrm{C}$. The next day, the cells were pelleted by centrifugation, washed with sterile water three times, and resuspended in $1 \mathrm{ml}$ of sterile water. From each sample, $25 \mu \mathrm{l}$ was plated onto a Luria broth plate and incubated at $30^{\circ} \mathrm{C}$ overnight. Growth or lack of growth was noted the following day.

Histopathology and blood chemistry. Organs from euthanized male and female animals were fixed in $10 \%$ neutral buffered formalin, processed, embedded in paraffin, sectioned at $5 \mu \mathrm{m}$, and stained with hematoxylin and eosin at Tufts University, Cummings School of Veterinary Medicine, Core Histology Laboratory (North Grafton, MA, USA). Hematoxylin stains nuclei and structures rich in nucleic acids gray to blue to dark purple. Eosin stains protein-rich regions of cells and tissues various shades of pink. All sections were examined in a blinded manner by a board-certified veterinary pathologist (G.B.). The organs sampled (and number sections examined) per animal included the following: stomach (2), small intestine (4), pancreas (1), large intestine (2 to 3), kidney (2), adrenal (1), liver (3), spleen (1), mesentery (1), brain (4 to 6), lungs (3 to 4), heart (entire), thymus (1 to 2 ), cortical bone (multiple), bone marrow (multiple), and growth plate (multiple). All tissues were examined for the following signs of microscopic disease and lesions: presence of nematodes/eggs, cellular immune or inflammatory infiltrates, cellular degeneration, apoptosis, and necrosis, lesion severity (none, minimal, moderate, or severe), lesion location (anatomic site), and incidental findings. After examination without knowledge of the groups, the study key was provided. In all animals and in all groups (males, females, IBaCC, and water), the following tissues were considered within normal limits by light microscopy: lymphoid or hematopoietic tissues (thymus, spleen, Peyer's patches, and bone marrow), central nervous system (brain), endocrine (adrenal), skeletal (bone and growth plates), cardiopulmonary (heart and lungs), upper digestive tract (squamous 
portion of the stomach, liver, or pancreas), and lower digestive tract (large intestine). The small intestines of all animals in all treatment groups contained minimal-to-mild, multifocal, plasmocytic to lymphoplasmocytic, and rarely eosinophilic infiltrates within the lamina propria. The infiltrates were interpreted as normal resident mucosal immune cells. There was no evidence of significant inflammation, degeneration, necrosis, fibrosis, or other toxicities in these tissues. Multifocal, minimal-to-mild mineralized foci were noted in the glandular epithelium of the stomach and the kidneys (renal tubules and collecting ducts) of all males and females in both the IBaCC and water groups, indicating it is not a consequence of treatment. These mineralized foci are known background lesions of laboratory hamsters (81). The glandular stomachs of females and males in both treatment groups contained particulates in the superficial mucus, of uncertain cause or significance. In a fraction of animals in all treatment groups (1 of 4 IBaCCtreated females; 2 of 3 water-treated females; 3 of 3 IBaCC males, and 2 of 4 water-treated males), minimal-to-mild lymphocytic serositis with reactive mesothelial cell hypertrophy was observed. The cause and clinical significance of this lesion was not apparent, but the lesion does not appear to be a specific adverse effect attributable to IBaCC treatment. None of these hamsters were infected and, indeed, in no section were any nematodes or nematode eggs seen.

Immediately after euthanasia, hamsters were exsanguinated by cardiac puncture, and blood was collected into SAFE-T-FILL capillary blood collection tubes-serum (RAM Scientific). Blood was allowed to clot for at least $30 \mathrm{~min}$ at room temperature before centrifugation. The collected serum was stored at $-80^{\circ} \mathrm{C}$ until further use. Serum biochemistry profiles were performed on a COBAS c501 chemistry analyzer (Roche Diagnostics, Indianapolis, IN, USA) using standard protocols.

Statistical analyses. Prism v. 7 was used for all graphs and two-group comparisons. Multigroup comparisons were carried out with SPSS v. 25. For all comparisons, including just two groups, except for the C. elegans data (due to only three samples per group), a one-tailed Mann-Whitney (nonparametric) test was used with the assumption that treatment reduced parasite burdens and fecal egg counts. For the $C$. elegans data, a one-tailed Student's $t$ test was used. For all comparisons involving more than one group, one-way analysis of variance (ANOVA) with a one-tailed Dunnett's posttest was used to compare groups relative to control or with Sidak's posttest for comparison between other groups.

\section{SUPPLEMENTAL MATERIAL}

Supplemental material is available online only.

SUPPLEMENTAL FILE 1, PDF file, 0.18 MB.

\section{ACKNOWLEDGMENTS}

This project was supported by the National Institutes of Health/National Institute of Allergy and Infectious Diseases grants R01AI056189 and R01Al50866 to R.V.A. and Agriculture and Food Research Initiative competitive grant no. 2015-11323 from the USDA National Institute of Food and Agriculture to R.V.A.

We thank Linda Wrijil and Sarah Ducat for the excellent histology services at Tufts University's Cummings School of Veterinary Medicine.

\section{REFERENCES}

1. Schulz JD, Moser W, Hürlimann E, Keiser J. 2018. Preventive chemotherapy in the fight against soil-transmitted helminthiasis: achievements and limitations. Trends Parasitol 34:590-602. https://doi.org/10.1016/j.pt.2018 .04.008.

2. Bethony J, Brooker S, Albonico M, Geiger SM, Loukas A, Diemert D, Hotez PJ. 2006. Soil-transmitted helminth infections: ascariasis, trichuriasis, and hookworm. Lancet 367:1521-1532. https://doi.org/10.1016/ S0140-6736(06)68653-4.

3. Ojha SC, Jaide C, Jinawath N, Rotjanapan P, Baral P. 2014. Geohelminths: public health significance. J Infect Dev Ctries 8:5-16. https://doi.org/10 .3855/jidc.3183.

4. Jourdan PM, Lamberton PHL, Fenwick A, Addiss DG. 2018. Soil-transmitted helminth infections. Lancet 391:252-265. https://doi.org/10.1016/ S0140-6736(17)31930-X.

5. Hotez P. 2008. Hookworm and poverty. Ann N Y Acad Sci 1136:38-44. https://doi.org/10.1196/annals.1425.000.

6. Passerini L, Casey GJ, Biggs BA, Cong DT, Phu LB, Phuc TQ, Carone M, Montresor A. 2012. Increased birth weight associated with regular prepregnancy deworming and weekly iron-folic acid supplementation for Vietnamese women. PLoS Negl Trop Dis 6:e1608. https://doi.org/10.1371/ journal.pntd.0001608.

7. Pullan RL, Smith JL, Jasrasaria R, Brooker SJ. 2014. Global numbers of infection and disease burden of soil transmitted helminth infections in 2010. Parasit Vectors 7:37. https://doi.org/10.1186/1756-3305-7-37.

8. Keiser J, Utzinger J. 2010. The drugs we have and the drugs we need against major helminth infections. Adv Parasitol 73:197-230. https://doi .org/10.1016/S0065-308X(10)73008-6.

9. Keiser J, Utzinger J. 2008. Efficacy of current drugs against soil-transmitted helminth infections: systematic review and meta-analysis. JAMA 299:1937-1948. https://doi.org/10.1001/jama.299.16.1937.

10. Kaplan RM. 2004. Drug resistance in nematodes of veterinary importance: a status report. Trends Parasitol 20:477-481. https://doi.org/10.1016/j.pt .2004.08.001.

11. Humphries D, Mosites E, Otchere J, Twum WA, Woo L, Jones-Sanpei $H$, Harrison LM, Bungiro RD, Benham-Pyle B, Bimi L, Edoh D, Bosompem K, Wilson M, Cappello M. 2011. Epidemiology of hookworm infection in Kintampo North municipality, Ghana: patterns of malaria coinfection, anemia, and albendazole treatment failure. Am J Trop Med Hyg 84:792-800. https://doi.org/10.4269/ajtmh.2011.11-0003.

12. Humphries D, Simms BT, Davey D, Otchere J, Quagraine J, Terryah S, Newton S, Berg E, Harrison LM, Boakye D, Wilson M, Cappello M. 2013. Hookworm infection among school age children in Kintampo North municipality, Ghana: nutritional risk factors and response to albendazole treatment. Am J Trop Med Hyg 89:540-548. https://doi.org/10.4269/ ajtmh.12-0605.

13. Humphries D, Nguyen S, Kumar S, Quagraine JE, Otchere J, Harrison LM, Wilson M, Cappello M. 2017. Effectiveness of albendazole for hookworm varies widely by community and correlates with nutritional factors: a cross-sectional study of school-age children in Ghana. Am J Trop Med Hyg 96:347-354. https://doi.org/10.4269/ajtmh.16-0682. 
14. Stothard JR, French MD, Khamis IS, Basáñez M-G, Rollinson D. 2009 The epidemiology and control of urinary schistosomiasis and soiltransmitted helminthiasis in schoolchildren on Unguja Island, Zanzibar. Trans R Soc Trop Med Hyg 103:1031-1044. https://doi.org/10 .1016/j.trstmh.2009.03.024.

15. Stothard JR, Rollinson D, Imison E, Khamis IS. 2009. A spot-check of the efficacies of albendazole or levamisole, against soil-transmitted helminthiases in young Ungujan children, reveals low frequencies of cure. Ann Trop Med Parasitol 103:357-360. https://doi.org/10.1179/136485909X398320.

16. Soukhathammavong PA, Sayasone S, Phongluxa K, Xayaseng V, Utzinger J, Vounatsou P, Hatz C, Akkhavong K, Keiser J, Odermatt P. 2012. Low efficacy of single-dose albendazole and mebendazole against hookworm and effect on concomitant helminth infection in Lao PDR. PLoS Negl Trop Dis 6:e1417. https://doi.org/10.1371/journal.pntd.0001417.

17. Edelduok EG, Eke FN, Evelyn NE, Atama Cl, Eyo JE. 2013. Efficacy of a single dose albendazole chemotherapy on human intestinal helminthiasis among school children in selected rural tropical communities. Ann Trop Med Public Health 6:413-417. https://doi.org/10.4103/1755-6783.127776.

18. Krücken J, Fraundorfer K, Mugisha JC, Ramünke S, Sifft KC, Geus D, Habarugira F, Ndoli J, Sendegeya A, Mukampunga C, Bayingana C, Aebischer T, Demeler J, Gahutu JB, Mockenhaupt FP, von SamsonHimmelstjerna G. 2017. Reduced efficacy of albendazole against Ascaris lumbricoides in Rwandan schoolchildren. Int J Parasitol Drugs Drug Resist 7:262-271. https://doi.org/10.1016/j.ijpddr.2017.06.001.

19. Diawara A, Halpenny CM, Churcher TS, Mwandawiro C, Kihara J, Kaplan RM, Streit TG, Idaghdour Y, Scott ME, Basáñez M-G, Prichard RK. 2013. Association between response to albendazole treatment and $\beta$-tubulin genotype frequencies in soil-transmitted helminths. PLoS Negl Trop Dis 7:e2247. https://doi.org/10.1371/journal.pntd.0002247.

20. Zuccherato LW, Furtado LF, Medeiros C da S, Pinheiro C da S, Rabelo ÉM. 2018. PCR-RFLP screening of polymorphisms associated with benzimidazole resistance in Necator americanus and Ascaris lumbricoides from different geographical regions in Brazil. PLoS Negl Trop Dis 12:e0006766. https://doi.org/10.1371/journal.pntd.0006766.

21. DiMasi JA, Grabowski HG, Hansen RW. 2016. Innovation in the pharmaceutical industry: new estimates of R\&D costs. J Health Econ 47:20-33. https://doi.org/10.1016/j.jhealeco.2016.01.012.

22. Lin WM, Addiss DG. 2018. Sustainable access to deworming drugs in a changing landscape. Lancet Infect Dis 18:e395-e398. https://doi.org/10 .1016/S1473-3099(18)30351-7.

23. Dayan AD. 2003. Albendazole, mebendazole and praziquantel. Review of non-clinical toxicity and pharmacokinetics. Acta Trop 86:141-159. https:// doi.org/10.1016/s0001-706x(03)00031-7.

24. Anonymous. 2019. Mebendazole. LiverTox: clinical and research information on drug-induced liver injury. National Institute of Diabetes and Digestive and Kidney Diseases, Bethesda, MD.

25. Karthickumar P, Balasubramanian P. 2017. Biofertilizers and biopesticides: a holistic approach for sustainable agriculture, p 269-298. Sustainable utilization of natural resources. CRC Press, Boca Raton, FL.

26. Griffitts JS, Aroian RV. 2005. Many roads to resistance: how invertebrates adapt to Bt toxins. Bioessays 27:614-624. https://doi.org/10.1002/bies .20239 .

27. Tabashnik BE, Carrière $Y$. 2017. Surge in insect resistance to transgenic crops and prospects for sustainability. Nat Biotechnol 35:926-935. https://doi.org/10.1038/nbt.3974.

28. Betz FS, Hammond BG, Fuchs RL. 2000. Safety and advantages of Bacillus thuringiensis-protected plants to control insect pests. Regul Toxicol Pharmacol 32:156-173. https://doi.org/10.1006/rtph.2000.1426.

29. Koch MS, Ward JM, Levine SL, Baum JA, Vicini JL, Hammond BG. 2015. The food and environmental safety of Bt crops. Front Plant Sci 6:283. https:// doi.org/10.3389/fpls.2015.00283.

30. Cappello M, Bungiro RD, Harrison LM, Bischof LJ, Griffitts JS, Barrows BD, Aroian RV. 2006. A purified Bacillus thuringiensis crystal protein with therapeutic activity against the hookworm parasite Ancylostoma ceylanicum. Proc Natl Acad Sci U S A 103:15154-15159. https://doi.org/10.1073/pnas .0607002103 .

31. Hu Y, Nguyen T-T, Lee ACY, Urban JF, Jr, Miller MM, Zhan B, Koch DJ, Noon JB, Abraham A, Fujiwara RT, Bowman DD, Ostroff GR, Aroian RV. 2018. Bacillus thuringiensis Cry5B protein as a new pan-hookworm cure. Int J Parasitol Drugs Drug Resist 8:287-294. https://doi.org/10.1016/j .ijpddr.2018.05.001.

32. Hu Y, Zhan B, Keegan B, Yiu YY, Miller MM, Jones K, Aroian RV. 2012. Mechanistic and single-dose in vivo therapeutic studies of Cry5B anthelmintic action against hookworms. PLoS Negl Trop Dis 6:e1900. https://doi.org/10.1371/journal.pntd.0001900.

33. Hu Y, Miller MM, Derman Al, Ellis BL, Monnerat RG, Pogliano J, Aroian RV. 2013. Bacillus subtilis strain engineered for treatment of soil-transmitted helminth diseases. Appl Environ Microbiol 79:5527-5532. https://doi.org/ 10.1128/AEM.01854-13.

34. Urban JF, Jr, Hu Y, Miller MM, Scheib U, Yiu YY, Aroian RV. 2013. Bacillus thuringiensis-derived Cry5B has potent anthelmintic activity against $A s c a-$ ris suum. PLoS Negl Trop Dis 7:e2263. https://doi.org/10.1371/journal .pntd.0002263.

35. Griffitts JS, Haslam SM, Yang T, Garczynski SF, Mulloy B, Morris H, Cremer PS, Dell A, Adang MJ, Aroian RV. 2005. Glycolipids as receptors for Bacillus thuringiensis crystal toxin. Science 307:922-925. https://doi.org/10.1126/ science. 1104444.

36. Adams CA. 2010. The probiotic paradox: live and dead cells are biological response modifiers. Nutr Res Rev 23:37-46. https://doi.org/10.1017/ S0954422410000090.

37. de Almada CN, Almada CN, Martinez RCR, Sant'Ana AS. 2016. Paraprobiotics: evidences on their ability to modify biological responses, inactivation methods and perspectives on their application in foods. Trends Food Sci Technol 58:96-114. https://doi.org/10.1016/j.tifs.2016.09.011.

38. Guimarães JT, Balthazar CF, Scudino $H$, Pimentel TC, Esmerino EA, Ashokkumar M, Freitas MQ, Cruz AG. 2019. High-intensity ultrasound: a novel technology for the development of probiotic and prebiotic dairy products. Ultrason Sonochem 57:12-21. https://doi.org/10.1016/j.ultsonch .2019.05.004.

39. Taverniti V, Guglielmetti S. 2011. The immunomodulatory properties of probiotic microorganisms beyond their viability (ghost probiotics: proposal of paraprobiotic concept). Genes Nutr 6:261-274. https://doi.org/10 .1007/s12263-011-0218-x.

40. Nataraj BH, Ali SA, Behare PV, Yadav H. 2020. Postbiotics-parabiotics: the new horizons in microbial biotherapy and functional foods. Microb Cell Fact 19:168. https://doi.org/10.1186/s12934-020-01426-w.

41. Hu Y, Miller M, Zhang B, Nguyen T-T, Nielsen MK, Aroian RV. 2018. In vivo and in vitro studies of Cry5B and nicotinic acetylcholine receptor agonist anthelmintics reveal a powerful and unique combination therapy against intestinal nematode parasites. PLoS Negl Trop Dis 12:e0006506. https:// doi.org/10.1371/journal.pntd.0006506.

42. Hu Y, Georghiou SB, Kelleher AJ, Aroian RV. 2010. Bacillus thuringiensis Cry5B protein is highly efficacious as a single-dose therapy against an intestinal roundworm infection in mice. PLoS Negl Trop Dis 4:e614. https:// doi.org/10.1371/journal.pntd.0000614.

43. Becker N. 2002. Sterilization of Bacillus thuringiensis israelensis products by gamma radiation. J Am Mosq Control Assoc 18:57-62.

44. Bevilacqua A, Corbo MR, Sinigaglia M. 2010. In vitro evaluation of the antimicrobial activity of eugenol, limonene, and citrus extract against bacteria and yeasts, representative of the spoiling microflora of fruit juices. J Food Prot 73:888-894. https://doi.org/10.4315/0362-028x-73.5.888.

45. Kang J, Liu L, Wu X, Sun Y, Liu Z. 2018. Effect of thyme essential oil against Bacillus cereus planktonic growth and biofilm formation. Appl Microbiol Biotechnol 102:10209-10218. https://doi.org/10.1007/s00253-018-9401-y.

46. Gilling DH, Ravishankar S, Bright KR. 2019. Antimicrobial efficacy of plant essential oils and extracts against Escherichia coli. J Environ Sci Health A Tox Hazard Subst Environ Eng 54:608-616. https://doi.org/10.1080/ 10934529.2019.1574153.

47. Soto $\mathrm{E}$, Ostroff $\mathrm{G}$. 2011. Use of $\beta$-glucans for drug delivery applications, $\mathrm{p}$ 48. In Větvička V, Novák M, Biology and chemistry of beta glucan: beta glucans-mechanisms of action. Bentham Science Publishers, Sharjah, United Arab Emirates.

48. Agaisse H, Lereclus D. 1994. Structural and functional analysis of the promoter region involved in full expression of the cryllIA toxin gene of Bacillus thuringiensis. Mol Microbiol 13:97-107. https://doi.org/10.1111/j.1365 -2958.1994.tb00405.x.

49. Lereclus D, Agaisse H, Gominet M, Chaufaux J. 1995. Overproduction of encapsulated insecticidal crystal proteins in a Bacillus thuringiensis spoOA mutant. Biotechnology (N Y) 13:67-71. https://doi.org/10.1038/nbt0195-67.

50. Wu C-C, Hu Y, Miller M, Aroian RV, Sailor MJ. 2015. Protection and delivery of anthelmintic protein $\mathrm{Cry} 5 \mathrm{~B}$ to nematodes using mesoporous silicon particles. ACS Nano 9:6158-6167. https://doi.org/10.1021/acsnano.5b01426.

51. Conlan JV, Khamlome B, Vongxay K, Elliot A, Pallant L, Sripa B, Blacksell SD, Fenwick S, Thompson RCA. 2012. Soil-transmitted helminthiasis in Laos: a community-wide cross-sectional study of humans and dogs in a mass drug administration environment. Am J Trop Med Hyg 86:624-634. https://doi.org/10.4269/ajtmh.2012.11-0413. 
52. Schär F, Inpankaew T, Traub RJ, Khieu V, Dalsgaard A, Chimnoi W, Chhoun C, Sok D, Marti H, Muth S, Odermatt P. 2014. The prevalence and diversity of intestinal parasitic infections in humans and domestic animals in a rural Cambodian village. Parasitol Int 63:597-603. https://doi.org/10.1016/j .parint.2014.03.007.

53. Inpankaew T, Schär F, Dalsgaard A, Khieu V, Chimnoi W, Chhoun C, Sok D, Marti H, Muth S, Odermatt P, Traub RJ. 2014. High prevalence of Ancylostoma ceylanicum hookworm infections in humans, Cambodia, 2012. Emerg Infect Dis 20:976-982. https://doi.org/10.3201/eid2006.131770.

54. Bradbury RS, Hii SF, Harrington H, Speare R, Traub R. 2017. Ancylostoma ceylanicum hookworm in the Solomon Islands. Emerg Infect Dis 23:252-257. https://doi.org/10.3201/eid2302.160822.

55. Garside P, Behnke JM. 1989. Ancylostoma ceylanicum in the hamster: observations on the host-parasite relationship during primary infection. Parasitology 98:283-289. https://doi.org/10.1017/S003118200006220X.

56. Hu Y, Ellis BL, Yiu YY, Miller MM, Urban JF, Shi LZ, Aroian RV. 2013. An extensive comparison of the effect of anthelmintic classes on diverse nematodes. PLoS One 8:e70702. https://doi.org/10.1371/journal.pone .0070702 .

57. Behnke JM, Rose R, Garside P. 1993. Sensitivity to ivermectin and pyrantel of Ancylostoma ceylanicum and Necator americanus. Int J Parasitol 23:945-952. https://doi.org/10.1016/0020-7519(93)90061-3.

58. Bansemir AD, Sukhdeo MV. 1994. The food resource of adult Heligmosomoides polygyrus in the small intestine. J Parasitol 80:24-28. https://doi .org/10.2307/3283340.

59. Elfawal MA, Savinov SN, Aroian RV. 2019. Drug screening for discovery of broad-spectrum agents for soil-transmitted nematodes. Sci Rep 9:12347. https://doi.org/10.1038/s41598-019-48720-1.

60. Roh JY, Choi JY, Li MS, Jin BR, Je YH. 2007. Bacillus thuringiensis as a specific, safe, and effective tool for insect pest control. J Microbiol Biotechnol 17:547-559.

61. Johler S, Kalbhenn EM, Heini N, Brodmann P, Gautsch S, Bağcioğlu M, Contzen M, Stephan R, Ehling-Schulz M. 2018. Enterotoxin production of Bacillus thuringiensis isolates from biopesticides, foods, and outbreaks. Front Microbiol 9:1915. https://doi.org/10.3389/fmicb.2018.01915.

62. Frederiksen K, Rosenquist H, Jørgensen K, Wilcks A. 2006. Occurrence of natural Bacillus thuringiensis contaminants and residues of Bacillus thuringiensis-based insecticides on fresh fruits and vegetables. Appl Environ Microbiol 72:3435-3440. https://doi.org/10.1128/AEM.72.5.3435 $-3440.2006$.

63. Kim M-J, Han J-K, Park J-S, Lee J-S, Lee S-H, Cho J-I, Kim K-S. 2015. Various enterotoxin and other virulence factor genes widespread among Bacillus cereus and Bacillus thuringiensis strains. J Microbiol Biotechnol 25:872-879. https://doi.org/10.4014/jmb.1502.02003.

64. EFSA Panel on Biological Hazards (BIOHAZ). 2016. Risks for public health related to the presence of Bacillus cereus and other Bacillus spp. including Bacillus thuringiensis in foodstuffs. EFSA J 14:e04524.

65. EFSA Panel on Additives and Products or Substances used in Animal Feed (FEEDAP). 2014. Scientific opinion on the safety and efficacy of Toyocerin (Bacillus toyonensis) as a feed additive for chicken for fattening, weaned piglets, pigs for fattening, sows for reproduction, cattle for fattening and calves for rearing and for rabbits for fattening. EFSA J 12:3766. https://doi .org/10.2903/j.efsa.2014.3766.

66. Tritten L, Silbereisen A, Keiser J. 2011. In vitro and in vivo efficacy of Monepantel (AAD 1566) against laboratory models of human intestinal nematode infections. PLoS Negl Trop Dis 5:e1457. https://doi.org/10.1371/ journal.pntd.0001457.
67. Sanders J, Xie Y, Gazzola D, Li H, Abraham A, Flanagan K, Rus F, Miller M, Hu Y, Guynn S, Draper A, Vakalapudi S, Petersson KH, Zarlenga D, Li RW, Urban JF, Ostroff GR, Zajac A, Aroian RV. 2020. A new paraprobiotic-based treatment for control of Haemonchus contortus in sheep. Int J Parasitol Drugs Drug Resist 14:230-236. https://doi.org/10.1016/j.ijpddr.2020.11 .004 .

68. Wei J-Z, Hale K, Carta L, Platzer E, Wong C, Fang S-C, Aroian RV. 2003. Bacillus thuringiensis crystal proteins that target nematodes. Proc Natl Acad Sci U S A 100:2760-2765. https://doi.org/10.1073/pnas.0538072100.

69. Stepek G, Lowe AE, Buttle DJ, Duce IR, Behnke JM. 2007. Anthelmintic action of plant cysteine proteinases against the rodent stomach nematode, Protospirura muricola, in vitro and in vivo. Parasitology 134:103-112. https://doi.org/10.1017/S0031182006001302.

70. Brenner S. 1974. The genetics of Caenorhabditis elegans. Genetics 77:71-94.

71. Bischof LJ, Huffman DL, Aroian RV. 2006. Assays for toxicity studies in C. elegans with Bt crystal proteins. Methods Mol Biol 351:139-154.

72. Marroquin LD, Elyassnia D, Griffitts JS, Feitelson JS, Aroian RV. 2000. Bacillus thuringiensis $(\mathrm{Bt})$ toxin susceptibility and isolation of resistance mutants in the nematode Caenorhabditis elegans. Genetics 155:1693-1699.

73. Hu Y, Platzer EG, Bellier A, Aroian RV. 2010. Discovery of a highly synergistic anthelmintic combination that shows mutual hypersusceptibility. Proc Natl Acad Sci U S A 107:5955-5960. https://doi.org/10.1073/ pnas.0912327107.

74. Huffman DL, Abrami L, Sasik R, Corbeil J, van der Goot FG, Aroian RV. 2004. Mitogen-activated protein kinase pathways defend against bacterial pore-forming toxins. Proc Natl Acad Sci U S A 101:10995-11000. https://doi.org/10.1073/pnas.0404073101.

75. Kao C-Y, Los FCO, Huffman DL, Wachi S, Kloft N, Husmann M, Karabrahimi V, Schwartz J-L, Bellier A, Ha C, Sagong Y, Fan H, Ghosh P, Hsieh M, Hsu C-S, Chen L, Aroian RV. 2011. Global functional analyses of cellular responses to pore-forming toxins. PLoS Pathog 7:e1001314. https://doi .org/10.1371/journal.ppat.1001314.

76. Kho MF, Bellier A, Balasubramani V, Hu Y, Hsu W, Nielsen-LeRoux C, McGillivray SM, Nizet V, Aroian RV. 2011. The pore-forming protein Cry5B elicits the pathogenicity of Bacillus sp. against Caenorhabditis elegans. PLoS One 6:e29122. https://doi.org/10.1371/journal.pone.0029122.

77. Chen C-S, Bellier A, Kao C-Y, Yang Y-L, Chen H-D, Los FCO, Aroian RV. 2010. WWP-1 is a novel modulator of the DAF-2 insulin-like signaling network involved in pore-forming toxin cellular defenses in Caenorhabditis elegans. PLoS One 5:e9494. https://doi.org/10.1371/journal .pone.0009494.

78. Camberis M, Le Gros G, Urban J, Jr. 2003. Animal model of Nippostrongylus brasiliensis and Heligmosomoides polygyrus. Curr Protoc Immunol Chapter 19:Unit 19.12. https://doi.org/10.1002/0471142735.im1912s55.

79. Lereclus D, Arantès O, Chaufaux J, Lecadet M. 1989. Transformation and expression of a cloned delta-endotoxin gene in Bacillus thuringiensis. FEMS Microbiol Lett 51:211-217. https://doi.org/10.1016/0378 -1097(89)90511-9.

80. Mirza Z, Soto ER, Hu Y, Nguyen TT, Koch D, Aroian RV, Ostroff GR. 2020. Anthelmintic activity of yeast particle-encapsulated terpenes. Molecules 25:2958. https://doi.org/10.3390/molecules25132958.

81. Mclnnes EF, Ernst H, Germann P-G. 2015. Spontaneous nonneoplastic lesions in control Syrian hamsters in three 24-month long-term carcinogenicity studies. Toxicol Pathol 43:272-281. https://doi.org/10.1177/ 0192623314532569. 